\title{
NO TRAÇAR DA MEMÓRIA: URBE E DITADURA em O Irmão Alemão, de Chico Buarque
}

Giovana Santos Lopes ${ }^{1}$

DOI 10.11606/issn.1981-7169.crioula.2017.126617

RESUMO: A memória é um dos recursos de ficcionalidade utilizados por Chico Buarque para compor O Irmão Alemão (2014), obra de segmento autoficcional. O personagem Ciccio é envolvido na rememoração, desde sua infância, na década de 1940, até o ano de 2013, em que o período da juventude, quase todo envolto às sombras da ditadura militar, é construído de maneira que expressa a relação do sujeito fragmentado com a urbe.

ABSTRACT: The memory is one of the resources of fictionality used by Chico Buarque to compose O Irmão Alemão (2014), work of autofiction segment. The character Ciccio is involved in the recollection, since his childhood in the 1940's until the year of 2013, when the period of youth, almost all shrouded in the shadows of the military dictatorship, is constructed in a way that expresses the relation of the fragmented subject with the urban.

PALAVRAS-CHAVE: Memória; Ditadura; Urbe; Ficção; Autoficção.

KEYWORDS: Memory; Dictatorship; Urban; Fiction; Autofiction.

1 Doutoranda em Letras pela Universidade Presbiteriana Mackenzie - Autoficção e Autobiografia ficcional: Um estudo sobre O Irmão Alemão e Diário da queda 


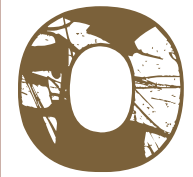

Irmão Alemão (2014), de Chico Buarque, é uma autoficção muito bem delineada e construída pelo autor. A história trata do personagem Francisco de Hollander, apelidado de Ciccio, que busca pelo seu irmão alemão, fruto de um relacionamento que seu pai, Sergio de Hollander, teve com uma jovem alemã, quando trabalhou como jornalista, em Berlim, na década de 1930. O enredo embaralha muito bem ficção e realidade, desde o início ao fim, o que proporciona ao leitor uma armadilha ficcional, ao passo que todo o percurso do personagem Ciccio é vinculado a inúmeros fatos efetivamente ocorridos na vida do autor. Chico Buarque utiliza, inclusive, documentos de sua família para compor essa "realidade fictícia". Esse "jogo" é oferecido ao leitor com o propósito da identificação de sua vida na obra; contudo é provido de ficcionalidade.

Não se trata apenas de uma espécie de "armadilha", tal qual um leitor teria inclinação a embrenhar-se durante a leitura da história, mas sim de verificar os recursos da ficcionalidade que Chico utiliza de maneira brilhante para compor a narrativa autoficcional.

Há tempos que se elaboram discussões acerca das fronteiras entre o real e o ficcional na literatura. Estratégias utilizadas por diversos autores para caracterizar a obra ou oferecer um jogo diferencial ao leitor motivam os debates do meio acadêmico e os interessados nos desdobramentos do universo literário. As teorias que envolvem tais temas, de forma geral, resultam na explicação de que a ficção será sempre elemento que representa a narrativa imaginária, a irrealidade, mesmo se disfarçada com artifícios que se confundem com a realidade. 
A biografia e a autobiografia são gêneros que caracterizam as obras que decorrem de dados reais, da vida de uma determinada pessoa. Todavia, a estratégia de mesclar dados da realidade, expressados por uma personagem romanceada, tem permeado o conteúdo de diversas obras da contemporaneidade. Há estudos que lidam com o termo autobiografia ficcional, entretanto, neste artigo, recorreremos ao termo desenvolvido desde a década de 1970, inicialmente, na França: autoficção.

Esse termo foi criado e apresentado por Serge Doubrovsky, professor de literatura e escritor francês; publicado, oficialmente, em 1977. Doubrovsky (2010) já pensava sobre o conceito de autoficção antes da publicação do termo, na capa de seu romance Fils, de 1977. O termo já aparecia em Le monstre, a primeira versão de Fils. No entanto, o conceito foi pensado, também, segundo discussões teóricas de Phillipe Lejeune, outro teórico e professor francês. Este discorre a respeito do pacto autobiográfico, de acordo com extenso estudo acerca da autobiografia, em Le Pacte autobiografique (1975), publicado primeiramente na revista Poétique.

Lejeune cria a discussão em torno da autobiografia, por ser um gênero praticamente desprezado, na França, entre o meio acadêmico e literário, sobretudo, desde a década de 1970. Desde suas primeiras pesquisas, o autor tinha como objetivo valorizar a autobiografia, e, da mesma forma, o papel do autor na literatura.

Para Lejeune (2008), a autobiografia tem por característica um pacto, em que afirma legitimar o princípio da veracidade da identidade do autor, narrador e personagem. Ele explica 
que o termo pacto tem similaridades ao de contrato, que, muitas vezes, sugere que há regras explícitas fixas e reconhecidas de comum acordo entre autores e leitores. Assim, todo leitor estaria certo de que a obra que está lendo é produto "fiel" da história de vida de um autor. Isso acaba por marcar uma distinção entre autobiografia e romance, em que, no primeiro, o compromisso do autor com a veracidade é primordial, sendo diferente do segundo, em que a veracidade não tem compromisso com o mesmo, tampouco com o leitor: "A autobiografia se inscreve no campo do conhecimento histórico (desejo de saber e compreender) e no campo da ação (promessa de oferecer essa verdade aos outros), tanto quanto no campo da criação artística. É um ato que tem consequências reais [...]" (LEJEUNE, 2008, p. 104).

Mais à frente, Lejeune (2008) cria um quadro em que mostra os efeitos da combinação do pacto com o emprego do nome próprio do autor (sua relação com o nome da personagem principal), e comenta que, por um acaso feliz, esse quadro foi analisado por Serge Doubrovsky, tendo este preenchido uma lacuna (ele denominou como "casa cega") que carecia de relação entre a autobiografia e o romance:

\begin{tabular}{|l|c|c|c|}
\hline \multicolumn{1}{|l|}{ Nome da personagem } & $\begin{array}{l}\text { - Diferente do nome do } \\
\text { autor }\end{array}$ & - Não é mencionado & $\begin{array}{l}\text { - Igual ao nome do } \\
\text { autor }\end{array}$ \\
\hline Romanesco & ROMANCE & Indeterminado & AUTOBIOGRAFIA \\
\hline Nenhum & $\ldots-\ldots-\ldots$ & AUTOBIOGRAFIA & AUTOBIOGRAFIA \\
\hline Autiobiográfico & - & & \\
\hline
\end{tabular}


Dessa, forma, surgem as indagações, feitas por Lejeune (1973):

As soluções que decretei como impossíveis seriam mesmo impossíveis? ... O herói de um romance declarado como tal poderia ter o mesmo nome que o autor? Nada impediria que a coisa existisse e seria talvez uma contradição interna que produziria efeitos interessantes. Mas, na prática, nenhum exemplo vem à mente... (LEJEUNE, 1973, In. NORONHA, (org). p. 22, 2014).

Assim, Doubrovsky cria o termo autoficção, o que inspirou Lejeune à observação, naquela década, nos anos de 1970, que o romance autobiográfico literário se aproximou da autobiografia a ponto de tornar muito indefinida a fronteira entre esses dois gêneros, tratando-se da "mentira verdadeira" à "autoficção". A esse respeito, Lejeune (2008) comenta, anos depois:

Esse quadro teve a sorte de cair nas mãos e inspirar um romancista (que também é professor universitário), Serge Doubrovsky, que decidiu preencher uma das casas vazias, combinando o pacto romanesco e o emprego do próprio nome. Seu romance Fils (1977) se apresenta como "autoficção" que, por sua vez, me inspirou. Não apenas por ser um livro admirável, mas também porque me dei conta... de que o lera mal. Acreditara em algo que talvez não devesse ter acreditado. Por essa razão, retomei o problema partindo do exemplo maquiavélico de Doubrovsky e de um outro caso tão complicado quanto o dele, embora mais ingênuo, o "romance" de Jacques Lanzmann, Le têtard (1976). Desse 
modo, pude observar um fenômeno mais amplo: nos últimos 10 anos, da "mentira verdadeira" à "autoficção", o romance autobiográfico literário aproximou-se da autobiografia a ponto de tornar mais indecisa do que nunca a fronteira entre esses dois campos. Essa indecisão é estimulante para a reflexão teórica: em que condições o nome próprio do autor pode ser percebido por um leitor como "fictício" ou ambíguo? Como se articulam, nesses textos, o uso referencial da linguagem, no qual as categorias de verdade (que se opõe a mentira) e realidade (que se opõe a ficção) permanecem pertinentes, e a prática da escrita literária, na qual essas categorias se esvanecem? (LEJEUNE, 2008, p. 59)

Em outras palavras, nesse sentido, entendemos que pode haver muitas "verdades" na autoficção, assim como muitas "mentiras" na autobiografia. Logo, se a autobiografia já se apresenta como gênero híbrido, a autoficção seria a prova de que esse hibridismo consagrou-se, e ainda nos dias atuais causa muita discussão. Se as divergências e discussões iniciam no que se refere ao termo, a conceituação e aplicação não ficam em segundo plano. A discussão parte da diferenciação entre autoficção e autobiografia, por entrelaçar os gêneros ficcional e referencial.

Para Doubrovsky (2010), a estrutura normal de uma narração autobiográfica separa enunciação (eu referente) e enunciado (eu referido) por um necessário intervalo (passado e presente). Na autoficção, por sua vez, conta-se vivendo, sob a forma de um fluxo de consciência que, naturalmente, seria impossível de se transcrever no fluxo do 
vivido-escrito, desenrolando-se no decorrer da história, ou seja, trata-se de uma ficção.

[...] a autoficção é uma variante pós-moderna da autobiografia, na medida em que se desprende de uma verdade literal, de uma referência indubitável, de um discurso historicamente coerente, apresentando-se como uma reconstrução arbitrária e literária de fragmentos esparsos da memória. (DOUBROVSKY. Apud VILAIN, 2015, p.212).

Porém, diferente da autobiografia, a autoficção não é apenas um relato retrospectivo da memória, mas apresenta um autor que se exibe ao leitor como um sujeito fragmentado que busca uma construção do "eu", ao embaralhar ficção e realidade, em diversas etapas de sua vida. Doubrovsky explica, em entrevista dada a Philippe Vilain, acerca da construção do "eu", relativizada pelo presente e memória/passado: "sob a aparência de uma continuidade do $e u$, as fraturas absolutas entre o que eu era no presente em diversas épocas da minha vida".

Um dos aspectos importantes a ser salientado em $\mathrm{O}$ Irmão Alemão (2014) é a memória, no tocante a autoficção. Assim, a rememoração é um desses recursos, dentre outros, da ficcionalidade que o autor apresenta ao leitor, como forma de identificação com a sua vida.

Booth (1980) comenta que, no texto literário, o narrador veste máscaras para ficcionalizar o real, como uma espécie de retórica da ficção; é a forma de construção, escolhida pelo autor que estabelece a intenção de realismo.

A mera ilusão da realidade, em si, não chega; a realidade compõe-se de tantas coisas e muitas 
delas não são dignas de apresentação com intensidade. Por outro lado, a intensidade em si não chega, embora seja algo que o romancista "inveja penosamente" ao dramaturgo, já que é uma "virtude em si". Seja qual for o grau de intensidade conseguido, tem que ser uma intensidade da ilusão de que foi apresentada genuína. $O$ princípio é a experiência sem limites, em expansão, "dar imagem e o sentido de certas coisas", é sempre metade do problema. Mas dá-los com intensidade, fazer com que o quadro da realidade imaginada brilhe com mais que penumbra, requer toda excelência da capacidade de composição do artista. (BOOTH, 1980, p. 61).

Nesse sentido, a ênfase na realidade é construída cuidadosamente sob uma ilusão ficcional, de maneira que a intensidade de tal construção seja a chave para a "virtude" do romancista, citada por Booth (1980). Para compor essa intensidade, que apresenta a ficção disfarçada de realidade, são utilizados alguns recursos como: a memória, os dados históricos, a descrição dos lugares (perfeitamente fiéis aos lugares reais), e sobretudo, no tocante às "escritas do eu", a relação da história do personagem com a história de vida do autor. Chico Buarque soube utilizar tais recursos com maestria. Ele utiliza a memória, relacionando-a com fatos de sua vida real, embaralhando-a com os fatos vividos pelo personagem Ciccio. É um dos recursos de ficcionalidade muito bem construídos pelo autor.

A história de O irmão alemão (2014) ocorre, em maior parte, na São Paulo da década de 1960. A cidade é descrita fielmente, conforme seu retrato físico e político durante esse 
período. Desde a infância, Ciccio descreve as ruas, o bairro, assim como sua casa. Ele descreve, já na juventude e também na idade adulta, alguns trajetos e bares que realmente existiram na época. Esse relato acerca da cidade e dos bares compõe a imagem fiel da cidade nesse período. Ciccio cita algumas ruas e avenidas, como a ruas Aurora, Augusta, da Direita, Maria Antonia, as avenidas Angélica, Paulista, Consolação, entre outras, e a partir dessa descrição elabora a correspondência com outros lugares da cidade de São Paulo, como o Cemitério da Consolação, o Pacaembu, os locais frequentados pelos universitários, ao redor da Rua Maria Antonia, o teatro Record, a praça da República, o Teatro Municipal, entre outros. Quase toda a história de O Irmão Alemão (2014) está atrelada à descrição da cidade de São Paulo, o que resulta no espaço como um dos condutores da narrativa, uma vez que o conduz à relação direta com a vida de Chico.

A memória, representada pelo espaço físico, dimensionado na capital paulistana, reproduz parte da vida do autor, ao passo que é ficcionalizada por meio do personagem Ciccio. Um exemplo disso, além de outros que pemeiam a história, é a casa dos Hollander. O narrador conta que a casa era cheia de estantes, espalhadas não somente no escritório de seu pai, como também por quase todos os cômodos:

Até então, para mim, paredes eram feitas de livros, sem o suporte desabariam casas como a minha, que até no banheiro e na cozinha tinha estantes do teto ao chão. E era nos livros que eu me escorava, desde muito pequeno, nos momentos de perigo real ou imaginário, como ainda 
hoje nas alturas grudo as costas na parede ao sentir vertigem. E quando não havia ninguém por perto, eu passava horas a andar de lado rente às estantes, sentia certo prazer em roçar a espinha de livro em livro. [...] Mamãe tratou logo de erguer estantes pelas paredes do sobrado, e ao engravidar decorou o quarto do bebê com livros de linguística e arqueologia, além da mapoteca dos espanhóis e dos chineses. Para meu quarto, dois anos mais tarde, reservou os escandinavos, a Bíblia, a Torá, o Corão e metros e metros de dicionários e enciclopédias. Depois de grande, ainda assisti ao advento de outras três estantes duplas para livros avulsos, ou inclassificáveis, que mamãe fez instalar nas paredes da garagem, pois nunca tivemos carro, nunca tivemos luxo. (BUARQUE, 2014, p. 16-18).

Além da relação acerca dos livros e estantes da casa da família de Chico Buarque, que, neste caso, faz alusão explícita à biblioteca de seu pai, a questão geográfica também é evidente. A antiga casa da família de Chico fica na rua Buri, a poucos quarteirões do Pacaembu, conforme conta Werneck, em reportagem biográfica sobre Chico Buarque (Hollanda, 2006, p. 21):

"Em julho de 1957, quando a família se mudou da Henrique Schaumann para a pequena e sossegada rua Buri, Chico passou a ter a poucos quarteirões de casa o Pacaembu, então o maior estádio de São Paulo".

Trata-se de uma ladeira, muito próxima das avenidas Paulista e Consolação, sendo um trajeto muito citado por Cic- 
cio em vários momentos da narrativa: "Ouvi o arrastar de suas sandálias atrás de mim na rua Augusta, da avenida Paulista, às ladeiras do Pacaembu, e da entrada de casa até meu quarto, onde se despiu sem pressa" (Hollanda, 2006, p. 41). Assim, a descrição de toda essa região central da cidade de São Paulo mostra que o autor conhece profundamente tais locais; mais do que isso, vivenciou-os.

É nessa vivência que a ambientação da personagem é construída. Há uma dimensão histórica atrelada ao espaço urbano, em que o autor revisita seu passado para compor o formato da narrativa: A ditadura é o fator histórico principal do romance. Chico utiliza esse momento da história brasileira de forma bastante precisa e descritiva resultando num cenário nostálgico e realista. A partir do capítulo 5, Ciccio começa a mencionar o regime da ditadura militar no Brasil, ao marcar a data de 31 de março de 1964, embora explique que a partir de 1968 o regime endureceu:

Posso dizer que minha vida acadêmica está bem encaminhada, embora por enquanto eu me limite a dar aulas de português no cursinho pré-vestibular em troca de uma mixaria. Talvez eu até consiga antes do previsto uma posição no corpo docente da faculdade, pois alguns professores foram afastados, outros se demitiram em solidariedade, fora os que sumiram, fugiram do país. Muitos alunos também largaram o curso, e persiste um clima de apreensão no meio universitário desde os acontecimentos de 1968, quando o regime endureceu de vez. Acabaram-se as passea- 
tas, bandeiras vermelhas dão cadeia, e nos bares onde ocasionalmente apareço não se toca em política. (BUARQUE, 2014, p.72-73).

Além de conectar a história dos personagens Ariosto, seu amigo desde a infância, Mimmo, seu irmão, e Trícita, namorada de Ariosto, que sugere terem sido presos e executados pelo regime da ditadura, Ciccio descreve a todo instante a opressão que a mesma causou à população. Ele não era integrante de grupos que agiam mais ativamente contra a ditadura, mas foi participativo, em alguns momentos:

Com o cerceamento do centro acadêmico, os alunos de filosofia, ciências e letras costumávamos nos encontrar nos bares das redondezas, onde o boca a boca nos deixava ao corrente das manifestações contra a ditadura que se realizavam vez ou outra pela cidade, obviamente sem a publicidade e a repercussão das marchas católicas do passado. E eu que não era de carregar faixas, ou de fazer coro a palavras de ordem, eu que na verdade nunca fui muito de andar em grupo, acabei tomando gosto por esses eventos. Circulava entre universitários e secundaristas, conheci militantes de organizações de esquerda, andei de braço com artistas, jornalistas, informantes, desocupados, malucos e moças insolentes com as pernas de fora que me lembravam a Maria Helena. Hoje mesmo, à saída das aulas, me excita deparar com a rua Maria Antônia fechada para o trânsito. (BUARQUE, 2014, p.49) 
Há muitas descrições que oferecem ao leitor uma noção real do que houve na época. Todavia, Chico Buarque consegue unir o humor, expressado pelo narrador, à cena de horror que dá a ideia do que a ditadura significou:

Minhoca aparece vestindo um jeans tão veIho quanto o meu, só que frouxo, desenxabido, dando por falta de corpo antigo. [...] A transversal está bloqueada por dois camburões e uma penca de policiais com armas pesadas, que interpelam os passantes e obrigam os motoristas a dar marcha a ré. Tento puxá-la pelo braço, mas a Minhoca se desvencilha e teima em seguir justamente por aquela rua. Ela parece mesmo se empenhar em ser detida na barreira, onde um sargento inspeciona sua flauta, depois a apalpa nos sovacos, nos seios e nos flancos, me deixando sem respiro enquanto se demora em suas partes íntimas. Ao ser liberada, a Minhoca desaparece tocando flauta além dos camburões, e se eu quiser alcançá-la terei de contornar mais que depressa o quarteirão, mesmo porque os policiais vêm subindo a rua onde sou o último civil à vista. Aperto o passo na rua do pensionato igualmente deserta e tenho a impressão de que a patrulha já dobra a esquina atrás de mim, muito embora não me conste que Fernando Pessoa seja um autor perigoso. Mas um novo pelotão começa a montar guarda na esquina seguinte, e só me falta surgirem cães farejadores de última geração, viciados em substâncias lisérgicas. O jeito seria buscar asilo no pensionato, mas ante as minhas orações a noviça não somente me nega entra- 
da como ameaça telefonar para uma delegacia de ordem pública. Encolhido na sombra da portaria, feito um mendigo adormecido na soleira, por enquanto não sou incomodado, e depois de um tempo convenho que não haveriam de mobilizar o Exército nacional para prender um merda como eu, com migalhas de entorpecente dentro de um livro de poesia. Mas por via das dúvidas guardo meu posto, tão cedo não me arriscaria naquela rua tão silenciosa, pacata demais. Escuto até os passarinhos do colégio ali perto, quando guincham pneus na esquina e vejo entrar na rua um camburão que breca de repente. E arranca num zás-trás, deixando um homem acocorado no meio da rua, um rapaz de cabelos pretos mais ou menos da minha idade. Com o corpo teso e as duas mãos no chão, como um corredor na linha de partida, o rapaz olha para um lado e para o outro, olha para o céu sem arco-íris. E ao primeiro tiro larga a mil em direção à rua de onde veio, talvez no intuito de voltar para casa dos amigos, da namorada, da mãe. Antes da esquina estaca, rodopia, corre de volta para cá, e é quando a fuzilaria se intensifica. Eu não gostaria de ver a sua cara, e de fato não vejo porque explode, a cabeça dele explode antes que eu possa fechar os olhos. Quando os reabro vejo o rapaz que ainda foge, mas sem a cabeça, é um corpo sem cabeça que corre uns dez metros, botando sangue pelo pescoço, pela barriga e pelo cu, quando tomba não muito longe do pensionato. Logo depois vem o segundo camburão, que pelo menos tem a misericórdia de não esmagar 
o corpo, antes de o recolher pela porta traseira e partir. (BUAQUE, 2014, p. 98-99).

Das muitas outras passagens da narrativa, em que a ditadura é mencionada, esse trecho é perturbador, e deixa claro ao leitor o ambiente terrível em que o país se encontrava na época. Ciccio leva tempo para recuperar o pensamento, diante da brutalidade da cena:

Apesar do calor, visto o pulôver e ainda assim me estremeço inteiro, olhando o vermelho do sangue apenas diluído nas poças d'água; Tocam sirenes, tocam os sinos de uma igreja, e a rua aos poucos recupera o movimento, os automóveis, os pedestres com suas sacolas, as babás com carrinhos de bebês, um moleque com a camisa da Seleção e uma bola debaixo do braço. Só eu não consigo me mexer, embora necessite falar com a Minhoca, que não sei por onde anda a estas horas. Pergunto as horas a uma senhora que passa com sua sombrinha, porque meu relógio parou ao meio-dia, mas ela me olha com repugnância. Num reflexo levo as mãos à cabeça e não a encontro, mas deve ser porque as mãos estão dormentes. Minhas pernas fletidas no chão parecem não ter ossos, o livro não pesa mais que as moscas no meu colo, meu corpo inteiro está insensível do pescoço para baixo, como se eu tivesse levado um tiro na espinha. Mas ainda que esteja aleijado para sempre, considero uma dádiva ter os olhos de ver o céu azul, os fiapos de nuvem, o balanço das saias plissadas das meninas do Colégio Des Oiseaux. A vida se renova 
aos meus ouvidos pelo fru-fru das saias e pelo canto de um bem-te-vi, que não é bem-te-vi, é uma flauta doce que toca Hello, Goodbye. E salto sobre a Minhoca como se a amasse muito, como jamais amarei mulher alguma. Beijo-a um, lábio, na flauta, nos dentes, na bochecha, na orelha, nos cabelos, digo-lhe um chorrilho de palavras que nem eu entendo. Melhor assim, porque se eu lhe falasse do que ia pelo meu pensamento, ela diria que estou perturbado, que amarrei um bode preto e que já deu no saco. A Minhoca deve ter razão, e durante meu abraço vejo como as manchas de sangue no asfalto se apagam com a borracha dos pneus de Volkswagens, Fords Galaxie e Simcas Chambord. E mesmo quando meu arrebatamento começa a esfriar, a Minhoca continua pendurada em meus ombros, com unhas que penetram nas malhas do meu pulôver, talvez porque neste momento também me ame sobre todas as coisas. Ou talvez porque pressinta o presente que tenho para Ihe dar (BUARQUE, 2014, p. 99-100).

Essa passagem do texto é aterrorizante, e, se a ela não fosse aliado o humor, teríamos uma conotação pesada e triste. Porém, o autor escolhe o humor como característica que acompanha toda a narrativa, sem, no entanto, deixar de apresentar a seriedade das questões atribuídas à ditadura:

Mas depois do seu casamento a Natércia começou a me evitar, e quando esta manhã me chama à sua sala é para que eu assine as duas vias da minha carta de demissão. Por motivos estrita- 
mente pessoais, diz a carta, para fechar um ciclo, buscar novos desafios, crescimento profissional etc. Houve uma denúncia que Ihe cabia apurar, e ela não hesitaria em abrir uma sindicância se fosse outro o funcionário envolvido no caso. Mas, em consideração aos nossos antigos laços, ela me oferece a oportunidade de deixar o emprego discreta e espontaneamente. Olhos seus olhos amarelos, procuro adivinhar que cartas ela tem na manga, estou inclinado a pagar para ver, mas a Natércia sustenta o olhar e não parece estar jogando. Enfim, desisto de me bater por um salário aviltante, assino os papéis em que abro mão de qualquer ressarcimento e saio da sala sem me despedir daquela ninfomaníaca. Passo na secretaria para recolher meus pertences e noto que todos ali já sabem da minha desgraça, até no olhar estrábico da faxineira me vejo como um proscrito. E caminho à deriva pela cidade, especulo sobre o real motivo da minha dispensa, a começar por compreensíveis ciúmes do marido da Natércia, um homem idoso, decano da faculdade de direito. Por outro lado essa mulher ambiciosa, que não faz muito se graduou doutora em letras, que até outro dia me enchia a paciência na cama com assuntos de semiótica, talvez me veja como um concorrente, agora que foi aberta uma vaga na cadeira de literatura comparada cujo titular se exilou no Chile. Não descarto mesmo a possibilidade de ela ter estimulado alunos meus a prestarem queixa contra mim, seja por atrasos constantes, excesso de faltas, bafo de álcool, ou até porte de LSD. Mas o mais grave, nos tempos que 
correm, é que uma demissão mal explicada deixa no ar a suspeita de que sou meio esquerdista, enquanto a Natércia, como toda cu de ferro, nunca sequer chegou perto do movimento estudantil. E se minha vida pregressa for esmiuçada por gente da atual reitoria, por força virá à tona minha proximidade com adversários do regime, até mesmo militantes da guerrilha urbana. Em breve meu nome cairá em alguma lista negra, escolas públicas me fecharão as portas, nem mesmo em colégio de padres serei bem-visto. Lembro-me então do Christian, penso que na Aliança Francesa os agentes da repressão não se atreverão a meter o nariz. Com um emprego na Aliança, por modesto que seja, terei respaldo para me aplicar nas minhas pesquisas à margem das intrigas do círculo acadêmico e à espera de melhores ares no país. (BUARQUE, 2014. p.129-130)

Quando Ciccio diz "caminho à deriva pela cidade", traz à tona a conotação que o autor atribui às andanças que o personagem faz em muitos outros momentos da narrativa: uma espécie de "eu à deriva", projetado à sombra de uma cidade que inicia um "caos" ao vivenciar um momento sofrido, como o da ditadura militar. Ciccio é um sujeito que tenta se encontrar ao iniciar a procura pelo irmão Serge, numa constante busca por alteridade, como se ao desvendar o que ocorreu com seu irmão alemão, descobriria a chave para entender muito a respeito de si, como seu distante relacionamento com o pai, por exemplo. Um sujeito transeunte de São Paulo, onde a cidade é o cenário perfeito de 
ficcionalidade que vista a relação da vida do autor com a vida da personagem.

A esse respeito, Simmel (1987, p.11) especifica: "A cidade é o espaço da mudança constante da alteridade, dos desafetos, e também da total indiferença para com o outro, da extrema individualidade em resposta à extrema objetividade". Nesse sentido, Ciccio percorre a narrativa, numa busca pelo irmão alemão atrelada às suas andanças e memórias pelas décadas de 1950 e 1960, em que o autor constrói um mapeamento do espaço urbano até o total compromisso com o espaço geográfico e cultural da época.

Chico Buarque utiliza uma espécie de jogo de espelhos, em que sua imagem é refletida no narrador Ciccio. Todo o período vivido intensamente pelo autor, mais ainda em sua juventude, serve de recurso ficcional, como uma espécie de encenação de si mesmo, delineando uma feição realista ao adentrar na história política e social em que o Brasil esteve inserido, na época da ditadura militar. Para tanto, Schollhammer (2011) explica:

O autor procura, em outras palavras, dar realidade à situação de observação, incluindo o leitor na exposição direta dos fatos, ao mesmo tempo em que questiona o perspectivismo cenográfico ao qual a observação está submetida e que afeta a veracidade e confiabilidade tanto do testemunho do autor, do narrador, do personagem quanto do leitor. (SCHOLLHAMMER, 2011, p. 112).

Nesse sentido, a construção ficcional de Chico Buarque utiliza uma relação estreita entre vida e ficção ao incluir fatos 
reais de sua vida à história vivida por Ciccio. Além disso, há as semelhanças já citadas, características da autoficção, com uso dos documentos da família Buarque de Holanda, por exemplo.

$\mathrm{Na}$ cena de assassinato do rapaz que tem a cabeça explodida, há um índice de uma realidade que acaba comprometendo a ficção. O leitor brasileiro tem informações suficientes de que a ditadura militar cometeu atrocidades a inúmeras pessoas; mas cenas de violência extrema, à luz do dia, em público, teriam mesmo ocorrido? Há o respaldo da ficção, e não cabe ao romance nenhum comprometimento com a resposta.

O autor lança mão desse recurso ficcional, e dá destaque a esse período, certamente, por tê-lo vivenciado amplamente. Assim, surge um questionamento: Ainda existem traços que configuram uma identidade nacional brasileira contemporânea, e, para tanto, faz-se necessário rememorar o passado? Ao tratar da recepção do leitor, em meio à identificação histórica, e também sendo fato notório tal vivência pelo autor, talvez seja este um dos papéis a que se propõe a ficção de Chico Buarque nesta narrativa.

Schollhammer (2011, p.15) explica essa característica da literatura que atualmente trata dos problemas sociais. Ela não exclui a dimensão pessoal e íntima, privilegiando apenas a realidade exterior; o escritor que faz a opção de ressaltar a experiência subjetiva não ignora a turbulência do contexto social e histórico. Chico Buarque utiliza esse recurso baseado no recorte da memória acerca da ditadura brasileira, e, como característica pecualiar 
à sua escrita, o humor se faz presente, mesmo em meio a questões historicamente trágicas.

O uso da representação do sujeito à deriva, na turba, fragmentado, expondo um fator da realidade histórica do país, coloca a narrativa do autor no limiar da produção literária contemporânea que tenta reinventar o realismo literário, assim como oportuniza uma maneira de lidar com a memória histórica.

Cabe-nos, ainda, salientar que a autoficção procura evidenciar, na sua proposta estética, as impossibilidades dos limites rígidos. Não se trata oportunizar palco para armadilhas em que o leitor possa embrenhar-se entre a ficção e o real, mas é esse "embaralhar" que exprime o contemporâneo, no sentido que estamos diante de novas propostas estéticas que tentam dar conta de uma realidade fragmentada, assim como o sujeito também fragmentado, da ficcionalidade. 


\section{REFERÊnCIAS BIBLIOGRÁfiCAS}

BUARQUE, Chico. O irmão alemão. São Paulo: Companhia das Letras, 2014.

BOOTH, Weyne Clayson. A retórica da fiç̧ão. Tradução: Maria Teresa Guerreiro. Lisboa: Arcádia, 1980.

LEJEUNE, Philippe. O pacto autobiográfico - De Rousseau à Internet. Jovita Maria Gerheim Noronha (Org.) Belo Horizonte: Editora UFMG, 2008.

NORONHA, Jovita Maria Gerheim (Org.). Ensaios sobre a autoficção. Belo Horizonte: Editora UFMG, 2014.

SIMMEL, Georg. "A metrópole e a vida mental". In: VELHO, Otávio Guilherme (org.) O fenômeno urbano. Rio de Janeiro: Guanabara, 1987.

VILAIN, Philippe. Défense de Narcisse. Paris: Grasset, 2005.

WERNECK, Humberto. Chico Buarque. Tantas palavras. São Paulo: Companhia das letras, 2006.

Submissão: 2017-02-10

Aceite: $2017-03-17$ 